\title{
Analysis of risk and threats to financial performance of enterprises in agro-industrial complex
}

\author{
Alexey Tabakov ${ }^{1}$ and Irina Fomina, ${ }^{1, *}$ \\ ${ }^{1}$ The Russian Presidential Academy of National Economy and Public Administration, Prospect \\ Vernadskogo, 84, Moscow, 119571, Russia
}

\begin{abstract}
The article discusses the risk assessment methods of financial performance of an enterprise. The essence of the main risks typical in enterprises of agro-industrial complex is described, sources of risk and factors affecting the financial performance are identified. A logical and probabilistic model of the risk of financial performance of an enterprise is suggested; factors and events that initiate the loss of profit, a decrease in sales revenues and an increase in the costs of enterprises in the agroindustrial complex are revealed. A method for calculating the significant values of risk probability and security areas for the formation of the financial performance of an enterprise is presented. An algorithm for calculating the dependencies was developed and it makes it possible to assess the critical values of indicators of financial and economic activity of an enterprise and the level of risk and threats to financial performance. The expediency of use of the authors' algorithm in order to optimize the amount and structure of costs and capital. It was stated that the suggested approach allows to monitor continuously the magnitude of risk and threats, to evaluate the effectiveness of measures which reduce the risk of having undesirable financial performance in an enterprise.
\end{abstract}

\section{Introduction}

Financial and economic activities of enterprises are based on production processes, within which the transformation of resources into final products, rendered services or performed works takes place. For the moment at the beginning of the production process, the real final results of technological operations, their records in the accounting system of business operations are still unknown. The systematization and classification of information concerning indicators of financial performance takes place with a delay.

The lack of necessary information allows us to obtain only a preliminary and very approximate assessment of financial performance of an enterprise in the future, what creates difficulties not only for forecasting the activity in an economic entity, but also for the adequate achievement of fiscal goals, especially for transnational corporations [1].

\footnotetext{
*Corresponding author: fominamail@mail.ru
} 
The main reason that does not allow assessing objectively the financial performance is the lack of reliable forecast information on the future market conditions of financial and economic activities of the organization. For the period when the final goods are obtained, the conditions for financial and economic activity may significantly change in comparison with the initial period of the production process. It is even more difficult to assess the development prospects of the market segment in which the enterprise's products are marketed.

Thus, the incompleteness of information on the achievement of the planned financial performance, the uncertainty of market conditions, and, accordingly, the restricted opportunity of forecasting the planned performance of the organization's activity and their subsequent achievement, are connected with the factors of entrepreneurial risk and the likelihood of the appearance and manifestation of negative events.

Limited, incomplete, fragmented information leads to the situation when the enterprise is unable to develop an adequate business strategy [2]. Accordingly, the lack of the business strategy has a negative impact directly on both the organization's activity and its financial performance, what significantly increases the emergence of all types of risks.

In agricultural production, the sources of risk have different nature and numerous forms of manifestation connected with changes in natural and climatic conditions, alternation of dry and cold years, risk of regional agricultural production. The enterprises of agroindustrial complex depend on productivity, storage conditions and processing of agricultural products, market sales. Changes in prices for resources and finished products significantly affect the sales revenue and financial performance of enterprises in the agroindustrial complex.

The instability of institutional environment, high transaction costs and the complexity of financial relations influence the uncertainty of the future financial performance of enterprises in agro-industrial complex in the conditions of a long process of economic activity which depends on the seasonality and what consequently results in the specificity of the shipment and storage of the produce which is short-lived [3].

Analysis of the risk for financial performance of enterprises in the agro-industrial complex should take into account the attitude of counterparties and investors to risk in addition to factors affecting the cost of production and sales of products. The formation of agro-industrial clusters, growth of investment attraction, introduction of advanced technologies for the production and processing of agricultural products provide an opportunity to reduce losses, increase the profitability of organizations [4].

The variety and frequency of all kinds of risks that complicate the activities of organizations in the agro-industrial complex make their identification necessary. In order to identify potential risks, as a rule, the factors influencing their level are studied. Such analysis allows us assessing the level of manageability of certain types of risks and developing measures which minimize them.

It is absolutely obvious that the performance of enterprises of agro-industrial complex is influenced by both external, mainly objective factors, and internal, mostly subjective factors. From the point of view of the opportunity of influencing the risks, in our opinion, the subjective factors can be attributed to the group of manageable ones, which the enterprises of the agro-industrial complex can influence in one way or another.

The analysis of risks that have an external impact on the activity of an enterprise involves the study of a set of various indicators (financial, non-financial, qualitative, quantitative indices). The assessment of the information about the external and internal environment of an enterprise is described in the KRISIS-analysis methodology, which makes it possible to determine the degree of its influence on business processes of an economic entity in crisis conditions for making effective decisions in management and strategic planning [5]. 
At the same time, the external environment determines both objective restrictions associated with the stages of public relations' development, and subjective limitations which, in particular, are connected with the sectoral policy for agricultural products [6], dynamics of exchange indicators [7], problems of the effectiveness of public procurement [8], and also the general level of innovation activity in the national economy [9].

The purpose of risk analysis of financial performance of an enterprise is to prevent the threats connected with possible losses of capital and resources invested in production, emergence of a situation when net profit also does not ensure other performance indicators (return on sales, return on assets, return on equity, capital structure indicators) that would meet the expectations of investors and shareholders.

The assessment of expected values of indicators of financial performance is carried out by means of extrapolation methods and statistical models based on correlation and regression analysis, estimation of the coefficients, analysis of factors, testing the hypothesis of adequacy of the dependences obtained. The instability of the conditions for financial and economic activity of enterprises in the agro-industrial complex, presence of nonlinearity in development of an enterprise reduces the accuracy of the forecast and the value of information obtained from the analysis of previously observed trends.

The reduction of the accuracy of the estimates obtained increases the likelihood of negative events in financial performance and entrepreneurial risk [10,11]. Improvement of the accuracy of the resulting forecast estimates requires taking into account changes in the structure, impact of structural changes on financial performance of enterprises. The estimates obtained with the help of algorithmic models, including the ARMA (p, q) - GARCH-M $(p, q)$ model [12 - 16], have more reliable predictive information that takes into account changes in internal and external conditions.

Since the results of economic activity of an enterprise are influenced by a large number of factors, a dynamic description of changes in indicators of financial performance requires the use of multivariate probabilistic models [17]. The mathematical apparatus that allows constructing models and assessing the magnitude of risk in multidimensional probabilistic systems, with different abnormal distribution laws of their parameters has not been developed sufficiently. Incompleteness of information and rare events restrain the use of methods of the theory of probability when the risk of complex dynamic systems including entrepreneurial risk is analyzed [18]. In order to analyze the risk, depending on the type and conditions of economic activity of the game theory, expert systems, logical and probabilistic models, and scenario technique are used in various combinations.

Further development of analytical methods for the assessment of development strategy should take into account strategic risks. Understanding the strategic risk can ensure the long-term activity of the enterprise in the market, the achievement of planned results based on the business goals. Strategic risk manifests itself through factors influencing the enterprise's ability to act, achieving the set goals of long-term planning of its activity.

The arrangement of conditions for continuous economic activity, development and growth of the capitalization of an enterprise is associated with the opportunity of attracting borrowed capital. At the same time, incomplete information for investors increases the price of borrowed capital, and the excessive attraction of borrowed funds under unfavourable conditions leads to risky situations associated with a decrease in financial performance and loss of net profit.

On the basis of acceptable risk concept, the analysis makes it possible to assess the critical values of the indicators of profit, profitability and capital, characterizing various levels and risk areas (risk-free area, high risk area, critical risk area). The risk assessment is made on the basis of criteria reflecting the indicative values of profit, return on capital, interest rate and return on financial instruments that appeared in the economy as a whole or in specific industries [19]. If the criteria are met, the magnitude of risk is seen as acceptable 
one and provides a secure risk level. In the event that the risk criteria are not met, the decisions are required to neutralize threats.

\section{Materials and method}

In order to assess the risk and stability indicators of complex systems, various methods of structural analysis are used, the most widespread of which are methods for development of event scenarios, methods for constructing threat trees, the Monte Carlo method, logical and graphic technique, and some other methods.

Structural analysis is based on the construction of a model that reflects the composition of the system's elements, their connections and relationships that ensure the functioning of the system. The performance of functions by elements in security and risk models is simulated using random events that reflect two polar opposite conditions for example: working condition or failure, positive or negative result, etc. The system model is described by means of logical functions that allow calculating probabilistic indicators and preparing information to justify managerial decisions which reduce risk and prevent threats to the system under analysis. One of the directions that allow assessing the stability of complex multidimensional systems, whose parameters have different abnormal distribution laws are the approaches which are founded on structural logical and probabilistic modeling of the system's functioning, logical and probabilistic risk theory with groups of incompatible events [20].

The logical and probabilistic model of the system risk includes a logical model and a probabilistic risk model that describe the scenario and the structural model of the system's risk. Since an organization is a complex economic system, then on the basis of the decomposition of the system, its subsystems are identified, in which the interaction of elements of one subsystem with others can be disregarded. The appearance (success) or deviation (failure) of the financial performance of an enterprise from a given level (invalidity of the enterprise) can be assessed as a result of the combination of events for subsystems by means of logical operations AND, OR, NO, taking into account possible losses of profit. On the basis of the analysis of invalidity of an enterprise for financial performance, the level of threats and risk areas are assessed.

\section{Results and Discussion}

Financial performance in monetary value shows the absolute economic effect in terms of profit from basic activities (operating profit, profit from sales), profit before tax and net profit. The centers of costs generation and the centers of profit generation (receipts from products sales) can be identified as the main elements of the generation of profit indicators.

The aggregate risk of an enterprise can be assessed with the help of analysis of risks associated with market pricing conditions, purchase prices for finished agricultural products offered by procurers (buyers) during the harvest period, ways of promotion of goods during sales revenue and preserving the harvest in order to expect a higher price in the future. When analyzing the aggregate risk, it is also necessary to assess the risks associated with the costs of production and sales of products, purchase prices for seeds, fuels and lubricants, fuel, spare parts, etc.

In order to construct structural, logical and probabilistic risk models, in which the organization does not receive the planned profit values (failure model), we introduce independent binary random variables: $X_{1}$ and $X_{2}$ for events connected with the unsuccessful generation of costs and sales revenues.

Random variables take values equal to 1 in case of failure, they are equal to 0 in case of success, with the corresponding probabilities: 


$$
\begin{aligned}
& \mathrm{P}\left(\mathrm{X}_{1}=1\right)=\mathrm{P}_{1}, \\
& \mathrm{P}\left(\mathrm{X}_{2}=1\right)=\mathrm{P}_{2} .
\end{aligned}
$$

The decrease in sales revenue as a result of changes in conditions in the market can be determined using the following relationship:

$$
\delta \mathrm{Vc}=(1-\mathrm{kv}) * \mathrm{~V}=\mathrm{rv}^{*}(1-\mathrm{kv}) * \mathrm{Z},
$$

where $\delta \mathrm{Vc}-$ decrease in sales revenue as a result of influence of non-random factors that determine price setting and sales volumes;

$\mathrm{kv}$ - decline rate in sales revenue in the planned period in comparison with the base period, taking into account the influence of non-random factors;

$\mathrm{V}$ - revenue from sales in the base period;

$\mathrm{Z}$ - costs of production and sales of products in the base period;

$\mathrm{rv}$ - ratio of sales revenue to costs.

The ratio of sales revenue to costs is connected with return on costs and is determined by the following ratio:

$$
\mathrm{rv}=\mathrm{V} / \mathrm{Z}=(\mathrm{Z}+\mathrm{R})=1+\mathrm{R} / \mathrm{Z}=\text { rens }+1,
$$

where $\mathrm{R}$ - operating profit (sales profit);

rens - return on costs.

The growth in production costs can be presented as an expression:

$$
\delta \mathrm{Zc}=(1+\mathrm{kz}) * \mathrm{Z},
$$

where $\delta \mathrm{Zc}$ - increase in production and sales costs;

$\mathrm{kv}$ - rate of increase in costs in the planning period in comparison with the base period, taking into account the influence of systematic factors;

$\mathrm{Z}$ - costs of production and sales of products in the base period.

Losses of profit from core activities (operating profit, profit from sales, $\delta \mathrm{RV}$ ) associated with the influence of systematic factors on revenue volumes will be as follows:

$$
\delta \mathrm{RVc}=\mathrm{kv} * \delta \mathrm{Vc}=(1-\mathrm{kv}) * \mathrm{rv} * \mathrm{Zc},
$$

The decrease in operating profit as a result of increased costs $(\delta \mathrm{RZ})$ can be calculated as follows:

$$
\delta \mathrm{RZc}=(\mathrm{kz}+1) * \mathrm{Zc} .
$$

Possible losses of operating profit associated with the influence of random factors on the generation of sales revenue and costs can be presented as follows:

$$
\begin{gathered}
\delta \mathrm{RZ}=\mathrm{P}_{1} *(\mathrm{kz}+1) * \delta \mathrm{Zc}=\mathrm{P}_{1} *(\mathrm{kz}+1) * \mathrm{Zc} \\
\delta \mathrm{RV}=\mathrm{P}_{2} *(1-\mathrm{kv}) * \delta \mathrm{Vc}=\mathrm{P}_{2} *(1-\mathrm{kv}) * \mathrm{rv} * \mathrm{Zc}
\end{gathered}
$$

The following states of an enterprise are possible.

State $1\left(\mathrm{~S}_{1}\right)$ - success in the generation of sales revenue and success in generation of the production costs:

$$
\mathrm{P}\left(\mathrm{S}_{1}\right)=\mathrm{P}\left(\mathrm{X}_{1}^{\prime} \mathrm{X}_{2}^{\prime}\right)
$$

Probability of success:

$$
\mathrm{P}\left(\mathrm{S}_{1}\right)=\left(1-\mathrm{P}_{1}\right) *\left(1-\mathrm{P}_{2}\right) .
$$

State $2\left(\mathrm{~S}_{2}\right)$ - failure in the generation of sales revenue and failure in the generation of production costs: 


$$
\mathrm{P}\left(\mathrm{S}_{2}\right)=\mathrm{P}\left(\mathrm{X}_{1} \mathrm{X}_{2}\right)
$$

Probability of failure:

$$
\mathrm{P}\left(\mathrm{S}_{2}\right)=\mathrm{P}_{1} * \mathrm{P}_{2}
$$

State $3\left(S_{3}\right)$ - failure in cost generation and success in revenue generation:

$$
\mathrm{P}\left(\mathrm{S}_{3}\right)=\mathrm{P}\left(\mathrm{S}_{1}\right)=\mathrm{P}\left(\mathrm{X}_{1}^{\prime} \mathrm{X}_{2}\right) .
$$

Probability of failure:

$$
\mathrm{P}\left(\mathrm{S}_{3}\right)=\mathrm{P}_{1} *\left(1-\mathrm{P}_{2}\right)
$$

State $4\left(\mathrm{~S}_{4}\right)$ - success in generating costs and failure in generating revenue:

$$
\mathrm{P}\left(\mathrm{S}_{4}\right)=\mathrm{P}\left(\mathrm{X}_{1} \mathrm{X}_{2}{ }^{\prime}\right)
$$

Probability of failure:

$$
\mathrm{P}\left(\mathrm{S}_{4}\right)=\mathrm{P}_{2} *\left(1-\mathrm{P}_{1}\right)
$$

The amount of possible losses of operating profit under various conditions of an enterprise can be calculated on the basis of the following dependencies:

$$
\begin{gathered}
\delta \mathrm{R}\left(\mathrm{S}_{2}\right)=\mathrm{P}_{1} * \mathrm{P}_{2} *[(\mathrm{kz}+1)+(1-\mathrm{kv}) * \mathrm{rv}] * \mathrm{Zc} \\
\delta \mathrm{R}\left(\mathrm{S}_{3}\right)=\mathrm{P}_{1} *\left(1-\mathrm{P}_{2}\right) *(\mathrm{kz}+1) * \mathrm{Zc} \\
\delta \mathrm{R}\left(\mathrm{S}_{4}\right)=\mathrm{P}_{2} *\left(1-\mathrm{P}_{1}\right) *(1-\mathrm{kv}) * \mathrm{rv} * \mathrm{Zc}
\end{gathered}
$$

The total loss of operating profit is equal to:

$$
\mathrm{SR}(\mathrm{S})=\delta \mathrm{R}\left(\mathrm{S}_{2}\right)+\delta \mathrm{R}\left(\mathrm{S}_{3}\right)+\delta \mathrm{R}\left(\mathrm{S}_{4}\right)=\mathrm{Zc} * \mathrm{Q}(\mathrm{P}),
$$

Here the value of $\mathrm{Q}(\mathrm{P})$ is calculated by means of the formula:

$$
\mathrm{Q}(\mathrm{P})=\mathrm{P}_{1} * \mathrm{P}_{2} *[(\mathrm{kz}+1)+(1-\mathrm{kv}) * \mathrm{rv}]+\mathrm{P}_{1} *\left(1-\mathrm{P}_{2}\right) *(\mathrm{kz}+1)+\mathrm{P}_{2} *\left(1-\mathrm{P}_{1}\right) *(1-\mathrm{kv}) * \mathrm{rv}
$$

The level of risk and threats to the generation of financial indicators can be performed by means of the analysis of the expected planned indicators, the amount of losses and the target value of indices of the amount of net profit or indicators of return on capital.

The target value of the net profit and the return on equity can be taken as the average return on equity in the industry, yield on government securities, and cost of borrowed capital.

Possible security areas and indicators of financial performance are presented in Table 1.

Table 1. Threats to financial performance of an enterprise.

\begin{tabular}{|l|l|}
\hline \multicolumn{1}{|c|}{ Security areas characteristics } & $\begin{array}{l}\text { Indicators of profit and economic efficiency } \\
\text { of an enterprise }\end{array}$ \\
\hline $\begin{array}{l}\text { Security area. } \\
\text { Risk level is acceptable and no risk } \\
\text { measures are required. }\end{array}$ & $\begin{array}{l}\text { After exposure to risk, the net profit is equal or } \\
\text { is greater than the required value. } \\
\text { The return on equity of an enterprise exceeds } \\
\text { the required level of return on equity. }\end{array}$ \\
\hline $\begin{array}{l}\text { High risk area. } \\
\begin{array}{l}\text { Heasures against risk are required. } \\
\text { management and getting the required } \\
\text { result. }\end{array}\end{array}$ & $\begin{array}{l}\text { After exposure to risk, the net profit is less than } \\
\text { the required value, but it is positive (the } \\
\text { enterprise receives net profit). } \\
\text { The return on equity of an enterprise is lower } \\
\text { than the required value of return on equity, but it } \\
\text { is still positive. }\end{array}$ \\
\hline Zone of critical risk. & After exposure to risk, there is no net profit, i.e. \\
\hline
\end{tabular}


Risk measures are required.

Low probability of positive results of risk management.

Risk management may not provide the desired result. it is less than zero, the enterprise is unprofitable. There is negative return on equity of an enterprise.

A secure level at which the magnitude of the risk is recognized as acceptable one and no measures reducing risk are required and it is considered to be insured if the risk criterion is met, i.e. the condition is met:

$$
\operatorname{RenKgn} \leq \operatorname{RenKg}-\delta \text { RenKg, }
$$

where RenKgn - target value of the return on equity, calculated according to the amount of net profit;

RenKg - planned value of the return on equity, calculated according to the amount of net profit;

$\delta$ RenKg - amount of decrease in the return on equity, calculated according to the amount of net profit.

In the case when the return on equity is less than the target value, but greater than zero, the organization is within a high risk area, i.e.:

$$
0<\operatorname{RenKg}-\delta \operatorname{RenKg}<\operatorname{RenKgn},
$$

If the value of the return on equity becomes lower than zero, then the organization is exposed to the threat of loss and a high level of risk for financial performance, i.e. enters the area of a catastrophic state:

$$
\operatorname{RenKg}-\delta \operatorname{RenKg} \leq 0,
$$

The amount of net profit on the assumption that other income and expenses of the organization consist only of interest paid for the used borrowed financial resources can be determined using the following relationship:

$$
\mathrm{Rg}=(\mathrm{R}-\mathrm{sZ} * \mathrm{SK}) *(1-\mathrm{C})=(\mathrm{Z} *(\mathrm{rv}-1)-\mathrm{sZ} * \mathrm{SK}) *(1-\mathrm{C})
$$

where $\mathrm{sZ}$ - price of borrowed capital;

SK - borrowed capital;

$\mathrm{C}$ - income tax rate.

Taking into account dependence (26), the value of return on equity calculated on the basis of net profit is equal to:

$$
\operatorname{RenKg}=(\mathrm{eK} *(\mathrm{rv}-1)-\mathrm{sz} * \mathrm{f}) *(1-\mathrm{C}),
$$

where $\mathrm{eK}$ - capital consolidation ratio, calculated as the ratio of costs to the capital of an enterprise $(\mathrm{eK}=\mathrm{Z} / \mathrm{K})$;

$\mathrm{f}$ - ratio of debt to capital of an enterprise.

Taking into account dependencies (22) - (27), it is possible to obtain expressions that allow calculating the probabilities of the state, levels of risk and threats of loss in financial performance when the enterprise is found in various security areas.

The critical levels of economic performance which they are found in the security areas can be determined by solving the following equation:

$$
\mathrm{eK} *(\mathrm{rv}-1)-\mathrm{eK} * \mathrm{Q}(\mathrm{P})-\mathrm{sz} * \mathrm{f}=\operatorname{RenKgn} /(1-\mathrm{C}) .
$$

The critical level of indicators, which determines the lower boundary of the high-risk area, is determined on the basis of the equation:

$$
\mathrm{eK} *(\mathrm{rv}-1)-\mathrm{sz} * \mathrm{f}=\mathrm{Q}(\mathrm{P}) * \mathrm{eK} .
$$


Dependencies (22) - (29) allow determining the critical levels of indicators characterizing the financial and economic activity of an enterprise, assessing the level of risk and threats to the generation of financial performance. The results of the analysis of external and internal conditions of economic activity make it possible to determine the managerial decisions, develop an optimal pricing policy, and optimize the amount and structure of costs and capital of an enterprise.

The suggested approach allows in the process of management of an enterprise to control continuously the magnitude of risk and threats, to evaluate the effectiveness of measures to reduce the risk of generation of financial performance of an enterprise.

\section{Conclusion}

The instability of economic and financial relations, lack of reliable forecast information on the state of the sales market, prices for finished products, raw materials and materials increase the uncertainty of the economic activity of an enterprise. The uncertainty of the conditions of financial and economic activity, probabilistic nature of the target indicators lead to the negative events which result in the loss of profit, emergence of the risk for financial performance of an enterprise.

The risk of generation and the threat of a decrease in financial performance and loss of capital are connected with the pricing for finished products, material, labor costs and borrowed resources of an enterprise. The increase in the duration of the technological process, seasonality, a large number of factors that influence the financial performance which are typical of enterprises of the agro-industrial complex, lead to a high level of risk. In an environment of high uncertainty, provision of business continuity requires the assessment and development of risk management measures.

The Russian Federation has one of the leading ranks in the world economy both according to the agricultural development level and the volume of agricultural production [21].

For this reason, we have presented this calculation model using as the example agricultural enterprises, what, however, does not limit its application for organizations in other sectors of the economy.

On the basis of the theory of logic and probabilistic risk management in the form of a scenario, a model is suggested for the assessment of the risk of failure in the generation of financial performance. This model is used for probabilistic assessment of the impact of external and internal conditions for price setting, revenue, costs and profits of an enterprise on the risk of financial performance generation of an enterprise of the agro-industrial complex.

The method is suggested for the calculation of critical values of risk probability indicators, which allow classifying threats into two types: the threats which require risk management, and threats that do not require the influence on risk factors. The classification of risk indicators provides a choice of options for alternative influences on factors, allows monitoring the risks and threats for the generation of financial performance.

\section{Acknowledgements}

The work was carried out in the framework of initiative research work. 


\section{References}

1. E.V. Dudukalov, G.O. Spabekov, L.V. Kashirskaya et al., Entrepreneurship and Sustainability Issues 8(2), 972-983 (2020) Doi: 10.9770/jesi.2020.8.2(59)

2. M. Kolbusa, Strategy Scout: How to Deal with Complexity and Politics During Strategy Development (Springer Science \& Business Media, Hamburg, Germany, 2013) Doi: 10.1007/978-3-642-35986-6

3. E.V. Dudukalov, M.I. Subhani, D.V. Ushakov, IOP Conference Series: Materials Science and Engineering 918, 012188 (2020) Doi: 10.1088/1757-899X/918/1/012188

4. T.V. Kushnarenko, A.V. Kaplina, A.N. Tabakov, I.B. Fomina, Clustering as an Integration Pattern of Business Activity, ERSJ XXI(1), 553-563 (2018)

5. A.N. Bobryshev, Economic Analysis: Theory and Practice 17(2), 285-307 (2018) https://doi.org/10.24891/ea.17.2.285

6. I.V. Terenina, D.D. Kostoglodov, L.D. Kiyanova,O.I. Usatkina, International Journal of Economics and Business Administration, 7, 325-338 (2019) https://www.um.edu.mt/library/oar/bitstream/123456789/45938/1/Tools_to_improve_t he_efficiency_of_import_substitution_in_the_agro_industrial_complex_under_econom ic_sanctions.pdf

7. Ch. Alexakis, T.V. Ignatova,A.V. Polyanin, Espacios 40(10), 17 (2019) Retrieved from http://www.revistaespacios.com/a19v40n10/a19v40n10p17.pdf

8. E.Yu. Zolochevskaya, E.A. Popova, E.M. Medyakova, IOP Conference Series: Earth and Environmental Science 272, 032110 (2019) Doi: 10.1088/1755$1315 / 272 / 3 / 032110$

9. S.P. Kyurdzhiev, E.P. Peshkova, A.A. Mambetova, FarEastCon 2018. Smart Innovation, Systems and Technologies, Springer, Cham 138, 444-454 (2020) https://doi.org/10.1007/978-3-030-15577-3_43

10. K.D. Strong, Zhaohao Sun, Annals of Data Science, 4(1), 1-17 (2017) https://doi.org/10.1007/s40745-016-0096-6

11. Jean-Louis Monino, Journal of Knowledge Economy, 1-12 (2016) https://doi.org/10.1007/s13132-016-0396-2

12. R.S. Tsay, An Introduction to Analysis of Financial Data with R (John Wiley \& Sons, 2012) ISBN: 978-0-470-89081-3

13. H. Georgakopoulos, Quantitative Trading with R: Understanding Mathematical and Computational Tools from a Quant's Perspective (Palgrave Macmillan, 2015) ISBN: 1137354070, 9781137354075

14. M. Rees, Business risk and simulation modelling in practice: using Excel, VBA and @ RISK (John Wiley \& Sons, 2015) ISBN: 1119084052, 9781118904053

15. C.S. Ang, Analyzing Financial Data and Implementing Financial Models Using $R$ (Springer, 2015) ISBN: 978-3-319-14075-9

16. J. Nakajima, Tails for Financial Time Series. Japanese Economic Review 63(1) (2012) Doi: 10.1111/j.1468-5876.2011.00537.x

17. I. Marcelin, I. Mathur, Journal of Banking and Finance 50(C), 528-546 (2015)

18. T. Aven, European Journal of Operational Research 253(1), 1-13 (2016) Doi: https://doi.org/10.1016/j.ejor.2015.12.023

19. T.V. Kushnarenko, A.N. Tabakov, I.B. Fomina et al., IOP Conf. Series: Earth and Environmental Science 403(1), 012074 (2019) Doi: https://doi.org 10.1088/1755$1315 / 403 / 1 / 012074$ 
20. E.D. Solozhentsev, Risk Management Technologies with Logic and Probabilistic Models (Springer, Dordrecht, Heidelberg, New York, London, 2012)

21. O.S. Sivash, D.V. Ushakov, M.I. Ermilova, IOP Conference Series: Earth and Environmental Science, 272(3), 032118 (2019) Doi: 10.1088/1755-1315/272/3/032118 